Prepared for Health, Risk and Society

\title{
Editorial:
}

\section{The Ethics of Socio-cultural Risk Research}

\author{
Authors: \\ *Nick Pidgeon, School of Psychology, Cardiff University \\ Peter Simmons, School of Environmental Sciences, University of East Anglia \\ Sophie Sarre, Department of Social Policy, London School of Economics and \\ Political Science \\ Karen Henwood, School of Social Sciences, Cardiff University \\ Noel Smith, Centre for Research in Social Policy, Loughborough University
}

Short title: Ethics and Risk Research

*Corresponding author:

Nick Pidgeon

School of Psychology, Cardiff University,

70 Park Place, Cardiff CF10 3AT

Email: PidgeonN@Cardiff.ac.uk

Acknowledgements: The preparation of this article was supported by the ESRC

Social Contexts and Responses to Risk (SCARR) Network under award RES-336-25-

0001. Additional support to Nick Pidgeon came from a Leverhulme Trust award F/00

407/AG. We wish to thank Corinne Squire, Alan Irwin, Andy Alaszewski and one anonymous reviewer for constructive discussions regarding this material. 


\begin{abstract}
In socio-cultural risk research, an epistemological tension often follows if real hazards in the world are juxtaposed against the essentially socially constructed nature of all risk. In this editorial we consider how this paradox is manifest at a practical level in a number of ethical dilemmas for the risk researcher. 1) In terms of strategies for seeking informed consent, and for addressing the power inequalities involved in interpretative and analytical work, researchers can find themselves pushing at the boundaries of standard understandings of ethical practices and ways of engaging informants in their studies. 2) Impact on participants is another key area of concern since the subject matter on which data are collected in risk research may be a source of uncertainty, anxiety or unwanted self knowledge. And 3) risk researchers also face the possibility of institutional repercussions of raising risk issues with people who usually normalise the risks, thereby stimulating distrust in the institutions or organisations with formal responsibilities for risk management. There are no simple formulae to guide the researcher in dealing with such ethical issues and paradoxes. It is important, though, to recognise their specificity in risk studies, including the ambiguous status of questions about vulnerability since judgements about 'who is vulnerable' and 'in what ways' are themselves influenced by the situational framings and understandings of participants and researchers.
\end{abstract}

KEYWORDS: SOCIO-CULTURAL RISK RESEARCH, ETHICS, EPISTEMOLOGY 
Research in the social sciences on risk and its perception has seen a steady evolution over the past 40 years, from an earlier concern with quantitatively investigating the ways in which various publics' risk perceptions might differ from evaluations of hazards as judged through formal risk analysis, to the emergence of more sociocultural approaches which pay far greater heed to the immediate social contexts which shape individual understandings of situations, and which lead them to be defined by people as risky or not. Socio-cultural risk research is also typically, though not exclusively, accompanied by different methodological commitments - specifically to more qualitative research designs, data gathering and analysis. However, such approaches, if they are to have any relevance to risks as they impact upon the real world, inevitably face an epistemological tension, albeit one which Rosa (2003) argues is present in almost all risk research. Put simply, while many hazards (e.g. road traffic, biologically active materials, major life transitions, climate change) do hold very real potential consequences for people, our knowledge and understanding of them, even that gained through formal risk or epidemiological analysis, can only ever be viewed as socially constructed. Hazards in the world may be real enough - but risk is inevitably socially conditioned. In this editorial piece we argue, based upon our collective experience of conducting a range of socio-cultural risk projects, that this epistemological tension is manifest at a practical level in a number of ethical dilemmas for the risk researcher, all of which need to be carefully considered in the design and methodology of any such research project.

Risk research in the policy domain has traditionally dealt with hotly contested topics, or differences in fundamental values between various participants and stakeholders, 
and has therefore always required a particular sensitivity to the politics of the ways in which outcomes of research might come to be portrayed (Fischhoff, 1990; Pidgeon and Gregory, 2004). In addition to this, routine debates about research ethics often involve little dispute about which research encounters simply require the application of standard ethical practices (informed consent, anonymity etc.) because participants or researchers are not in any significant sense vulnerable to physical or psychological harm, and those which will require more elaborated consideration because issues of vulnerability directly arise (work with victims or perpetrators of sexual abuse being a good case in point). Most socio-cultural risk research, by contrast, occupies a far more ambiguous status with regard to the issue of vulnerability, precisely because "who is vulnerable' and 'in what ways' are themselves the outcomes of the way the situation comes to be framed and understood by both participants and researchers.

\section{The researcher's agenda and informed consent}

It is now well understood that declaring the precise topic under investigation at the recruitment stage, in either quantitative or qualitative research, may lead to bias or exclusions in the sample obtained, either towards those with a particular stake or interest in the issue at hand, or away from those who feel they have nothing to contribute on the topic. More importantly, though, research participants may well not ordinarily frame as 'risky' aspects of their daily lives, such as living near to a chemical plant, using a routine medication, making a career change, or even contemplating marriage, even though some others (risk analysts, clinicians, social work professionals etc.) clearly might. Accordingly, socio-cultural investigations often stress a need to elicit, at least initially, participants' own frames of reference and 
understandings of the problems under investigation, while simultaneously aiming not to construct the object of inquiry (as 'risk') simply by enquiring about it (Henwood, Pidgeon, Sarre, Simmons and Smith, forthcoming). This can lead researchers to down-play, to a greater or lesser degree, the focus on risk at the point of recruitment, gaining of consent for participation, and the initial (or even all) data gathering steps. Accordingly, participants might be informed - as we have done at times in our own risk projects - that a project is about 'environmental issues', 'choices' or 'decisionmaking' in relation to their particular topics of study (e.g. nuclear power, intimate relationships, or experiences with employment). While such strategies do not aim to actively mislead participants in advance of conducting an interview or focus group, and any direct queries from participants about the topic of study should be answered honestly by researchers, in so doing researchers may be considered, at least in part, guilty of the sin of omission. This has implications for informed consent - how much information does 'informed consent' depend upon, and under what circumstances can the main purpose of the research be legitimately withheld until the research interview is underway or even completed? To cite just one example from research on mental models of hazardous chemicals in the workplace, generating a detailed mapping of participants' own frames and understandings and, crucially, possible knowledge gaps or misunderstandings (relative to what is known through risk analysis and expert elicitation about the hazard) is a key first step in the design of risk communications that are genuinely sensitive to audience concerns (Cox, Niewöhner, Pidgeon, Gerrard, Fischhoff and Riley, 2003). Viewed from the perspective of utilitarian ethical principles, the anticipated benefits to be gained from health protection through systematically constructed risk messages to a wider vulnerable population might be 
thought to offset the problem of giving only partial information (at the outset of a study at least) to those who make up the study sample.

As a general practice, and in line with standard guidance on ethics in social research practice (SRA, 2003) risk researchers would consider it important to do such things as inform their study participants about how their words might be used (to illustrate reported findings), and, in advance of an interview or other research encounter, that they can curtail their involvement at any time. This, at least, is essential, and as Graham, Grewal and Lewis (2007) suggest, participants' main concern is often whether sensitive or personal information will be sought and the kinds of topics that will be covered, rather than issues relating to the purpose of the research. Additionally, where an interview deals with symbolically and affectively charged subjects (thus running the risk of raising health or environmental anxieties), or where evidence exists of a clear source of potential harm for some participants, it is also considered good practice to provide a balanced range of sources of further information about the topic at the end of each interview.

A more subtle consent issue derives from the observation, hinted at above, that participants might be operating with very different understandings of 'risk' than researchers. If this is so, even when researchers are entirely explicit at the outset about the purpose of a study, there must be doubt about the extent to which properly informed consent can be claimed. In such circumstances, researchers find themselves pushing at the boundaries of the principle and practice of informed consent, and struggling for ethical ways of engaging and involving participants in their studies without assuming full equivalence between their understandings and those of 
researchers themselves. Although, to an extent, this situation is common to much social scientific research, it seems particularly acute for risk researchers, given the possibility that the issue under investigation might involve real (health, psychological or social) consequences in the future for the people who have taken part. For example, if there is a miscalculation on a researcher's part regarding what, when, and how much to tell participants, then this could have consequences for participants' sense of interpersonal trust and self-integrity (both of which are integral to psychological wellbeing).

How might such miscalculations occur? At the simplest level, despite explaining their purpose researchers cannot be entirely certain that participants understand the extent to which details of their personal histories could be used to exemplify key aspects of the data analysis. Qualitative research (unlike quantitative) also has to face threats to assurances made to safeguard anonymity, including the possibility that a participant who does not wish to be identified might nevertheless be recognised from personal details, even when pseudonyms are used in final reports or published papers. Such threats can be particularly acute when working within specific, locally-defined, communities where research participants may know each other well, or when working with institutional stakeholders. Regarding the latter, institutional details (even something as bland as 'government radiation expert') might be particularly revealing when there is a very small pool of individuals to engage about a subject. Equally, a researcher cannot be sure whether information provided at the start of the research addresses questions that participants might have after fully reflecting upon both their participation and the ways in which discussions in an interview or focus group were 
framed. This is not merely a question of information and understanding but of the way that power permeates the research relationship and is enacted in its routine practices.

Data analysis takes the issue of power further, in that it raises not merely the issue of power differences in terms of the control of information, but also the challenge of epistemic inequalities, as the following quotation indicates:

"Anytime a researcher imposes his or her own framework of analysis on the storied accounts gleaned from other people [...] questions arise about ownership (whose story is it now?) and validity (in what ways has that story been altered through the process of interpretation and the necessity of choosing selected samples of discourse to use as supporting evidence and illustrations?).” (Sharf 1999 p.248)

The existence of variability between researchers and participants in relation to the ways in which both 'risk' and the wider research topic can be understood therefore brings challenges for interpretive practice. Data analysis in socio-cultural research typically relies on a degree of inference by the researcher(s), so giving participants greater knowledge about what will be sought at the analysis stage may serve to redress a power imbalance. One means of meeting these ethical concerns is, of course, to present the aims and scope of the research, including its framing as being about risk, as transparently as possible to participants at the outset. Participants can also be involved more directly as research partners in the construction of an analytical understanding, using practices such as member checking "whereby data, analytic categories, interpretations, and conclusions are tested with members of those 
stakeholding groups from whom the data were originally collected" (Lincoln and Guba, 1985, p. 314). Lincoln and Guba advocate this as a procedure for enhancing the credibility of the conclusions drawn from qualitative research, while others see this process not as a validation in the form of direct corroboration (since good theoretical analysis inevitably generates something which transcends the direct experience of participants' accounts) but more as a check against poor interpretation and misrepresentation of participants' views (Murphy and Dingwall, 2003). Seen as more than just a checking device, however, this process might also help to address epistemic power inequalities in the research relationship. All of these interpretive/analytic issues have parallels in social scientific research practice more generally but again, we would argue, are magnified in research on risk - where constructed meanings are often juxtaposed with very real potentials that can exist for harm - and so demand greater attention and thought from researchers and researched alike. They also point, more specifically, to a need for further research on participants' views on the ethical questions raised in relation to risk issues and risk research (see e.g. Corden and Sainsbury, 2005).

\section{Impacts on participants}

As we have suggested already, researching risk may entail raising potential risks to the individuals who participate in the research, particularly when taking part in interviews or focus groups with researchers and others. The ethics of social research normally require the researcher to ensure that there is minimal risk to participants, and that this is certainly no greater than would be ordinarily faced in their day-to-day 
lives. The statement of ethical practice for the British Sociological Association states that:

"In many of its forms, social research intrudes into the lives of those studied. While some participants in sociological research may find the experience a positive and welcome one, for others, the experience may be disturbing. Even if not harmed, those studied may feel wronged by aspects of the research process. This can be particularly so if they perceive apparent intrusions into their private and personal worlds, or where research gives rise to false hopes, uncalled for self-knowledge, or unnecessary anxiety" (BSA, 2004, p. 4).

Likewise, the Research Ethics Framework published by the UK Economic and Social Research Council (2005, p. 8-9) notes that research that would induce "psychological stress [or] anxiety" cannot be considered to pose "minimal risk".

Some susceptible individuals may experience such anxiety simply as a result of the experience of being interviewed; others may suffer anxiety (noted above) about the possible disclosure of personal information. Qualitative research interviews can be particularly sensitive in this respect in that they may entail, or at least encourage, a greater degree of personal disclosure or self-scrutiny than more structured methods of data collection such as questionnaires. Ordinarily the researcher is expected to anticipate and minimise such risks, as well as to take steps to ameliorate significant anxiety or other harms if they suspect these have occurred. Of course, many qualitative interviews do not entail extensive personal disclosure, and equally we cannot automatically assume that, for example, quantitative surveys do not result in 
self-scrutiny (many undoubtedly do!). But the dynamics of the qualitative, in particular the in-depth biographically-focused interview, do lend themselves to greater disclosure, whether intentional or unintentional. Moreover, in risk research, an additional concern is whether the subject matter of the interview may be a particular source of either anxiety and/or unwanted self-knowledge. A particular ethical challenge presented to researchers investigating experiences of risk occurs, then, because of the way that asking a question in terms of risk may itself engender doubt and uncertainty in relation to the practice or situation so framed.

One can identify at least two different ways in which this may create ethical dilemmas for the researcher attempting to study how people deal with 'risk' in their everyday lives. The first, and most readily recognised dilemma is that by introducing these topics for discussion the researcher may directly induce or raise levels of anxiety that would otherwise not be present. When individuals are required to reflect on sources of risk in their everyday lives they are being asked to bring into consciousness experiences or situations that may represent a specific threat (however unlikely) to them or to something that they value, and thereby to their emotional or physical wellbeing. For example, an important part of any discussion of perceptions of the risks of cancer from radiation might be a consideration of how a participant felt about any relatives or friends who had previously suffered from this. The forms of contextual socio-cultural risk research discussed here (i.e. often interview-based, with a micro-level / contextual focus) may well be particularly vulnerable to this ethical dilemma - since they seek explicitly to find and explore referents for risk which have a resonance with (or direct connections to) people's own life-worlds. 
Of course, raising the topic of risk need not necessarily provoke excess or unwanted anxiety. In some cases participants will have already thought in depth about these issues (if not always in the language of risk), or have developed deliberate strategies for coping with risks with which they live everyday ( $c f$. Giddens 1991; Langford, 2002). For others, the degree of self awareness brought about by new insights into risk in relation to their everyday lives will be constructive: moderate levels of concern may be entirely beneficial for some people, being necessary before they will engage in systematic decision-making about an issue (e.g. Janis and Mann, 1977). All of these cases are likely to engender a robust attitude towards discussing 'risk' with the researcher.

For some, however, the frames of understanding that they ordinarily bring to bear upon the issue may indeed be unsettled in adverse ways, while others may have developed discernibly self-protective mechanisms even as a conscious strategy, sometimes characterised in interviews by phrases such as 'head-in-the-sand' or 'ignorance is bliss', which may be more vulnerable to too much direct reflection. Under these latter circumstances, asking people to examine their experience of and responses to specific sources of risk in their life therefore runs the risk of worrying and upsetting at least some people, the effects of which may only fully be felt after the researcher has departed. It is not only the relatively unusual subject of living in close proximity to a nuclear power station that can present the potential for such anxiety in participants. In a second example, of an investigation into how individuals perceive intimate relationships in terms of risk, interview questions probing people's awareness of and ways of managing the risks of entering into a committed, cohabiting relationship might increase uncertainty and anxiety about their relationship, 
particularly in those susceptible to such worries and who manage this anxiety with the kind of avoidance or denial strategies noted above. Similarly, questioning individuals closely on their career decisions may provoke, in those who are susceptible, discomfort or anxiety about current or future decisions or about those already made: for example, during one follow-up interview that was conducted, one participant explained that until that time he had not thought about career change in terms of risk but that the research had given him "quite an interesting view on how I might see these things in the future". This illustrates the potential impact of participation in risk research - the possibility that participants subsequently develop a heightened awareness of current or future vulnerability to risk and the extent to which it has an adverse effect, whether through anxiety and ambivalence, on subsequent experience, or even on behaviour. While participants might not display any overt signs of distress during interviews, closer analysis of data can reveal indications of unvoiced anxiety (often indexed through hesitations at critical moments, or even light-hearted or humorous remarks), suggesting that the impact of a topic is not completely neutral for all participants ( $c f$ Zonabend, 1993; Irwin, Simmons and Walker, 1999).

At times the ethical issue of anxiety and its relationship with vulnerability becomes turned on its head. Three of the present authors (Pidgeon, Henwood and Simmons), investigating the life narratives of people living in close proximity to a nuclear power station, found that the person who might have been expected to be most sensitive to being upset by the issues raised, a participant who revealed at interview that they were suffering from terminal cancer, had explicitly wanted to be interviewed so that they could express to someone their views, doubts and concerns about the cause of their condition. In this regard, Hallowell (2006) also points out, based on research on living 
with the risk of ovarian cancer, that there may be significant emotional impact on the researcher of such research encounters. Like the participant in the nuclear power study, the women in Hallowell's study were also keen to tell their story despite the emotion that accompanied the telling - emotion that preceded and went beyond the research encounter.

Another perspective on this question arises, in relation to partnership choices, when researchers know from previous studies that cohabitants are not all well informed about their legal status (Lewis, Datta and Sarre 1999). Cohabitants can effectively be 'at risk' in some way and yet not know it. If, for example, a cohabiting woman in the UK states that she is a common law wife and has rights to her partner's property or a cohabiting father expresses the belief that he has paternal rights because he is on his child's birth certificate, the researcher faces an ethical dilemma about whether to inform people of the fact that their situation is not as they think it is (either by telling them directly or directing them to sources of information), or whether taking such action could create conflict and put the relationship at risk?

The question that this poses is, given that individuals confront everyday risks with greater or lesser anxiety, in what situations or in what ways is provoking uncertainty or anxiety, or even recasting the issue completely for participants, an ethical problem, and when is it acceptable or perhaps even desirable? This may be a question of the intensity or persistence of feelings of unease associated with acknowledging an uncomfortable aspect of their life situation. More than this, however, could anxiety elicited by the probing of the researcher also have the potential to threaten the stability of the identity that an individual has constructed, in part, perhaps, to enable them to 
live with risk? This also raises the additional question of the extent to which the researcher's duty of care extends beyond the initial research encounter?

A second, perhaps less obvious dilemma concerns not only the personal but also the institutional repercussions of detailed socio-cultural risk research: raising risk issues with people who ordinarily 'normalise' them in various ways may only serve to stimulate distrust in those institutions or organisations with formal responsibilities for managing the risk. Consider communities living in close proximity to decommissioning industrial facilities which require long-term and complex remediation efforts, because of persistent contamination, as part of a transition to other uses. Such a situation arises, for example, with almost any legacy site associated with the early civilian and military nuclear programmes across the world. Seen from the perspective of the site managers at least, good relations with the local community will be critical in ensuring that such a transition is a smooth one. Simply asking people to revisit events and experiences associated with a site and its management that may have raised concerns about risk in the past, because of their activities and poor practices may also, unintentionally, contribute to elevated levels of concern about the current management of the site and stimulate scepticism and distrust ( $c f$ Poortinga and Pidgeon, 2003) towards site operators or regulatory authorities. Depending upon the position and social influence of the individual within the community studied, were this concern and distrust to result in public criticism or action, it could conceivably also have political and practical implications for those responsible for managing site decommissioning. Furthermore, dependant upon the timing of other events, it could have implications for related politically sensitive issues: such as the siting and construction of needed long-term waste disposal 
facilities, or even the development of new industrial uses for a site. In this latter instance, the researchers could also face the potential but more generic problem of their research being appropriated and used (or misused) by parties in a partisan political debate. The ethical question here - particularly salient with risk research, where arguments about 'risk' can often stand as a proxy for wider values-based conflicts between competing groups - is whether the researchers have a duty to avoid potentially influencing the wider study context in ways which at least some institutional stakeholders might construe as negative when the research was not intended or designed to be an intervention or action-based project?

\section{Conclusion}

There is no simple formula or set of guidelines that can assist the risk researcher in addressing some of the ethical issues that we have attempted to share here. We began this editorial by suggesting they derive from an epistemological tension between the real and constructed faces of 'risk'. While some socio-cultural researchers might happily choose to ignore its implications, our experiences working with our own projects, as well as in observing the work of others such as graduate students (who often struggle with the epistemological tensions that a socio-cultural orientation towards risk brings), suggests that for many risk researchers these dilemmas cannot be readily ignored. Accordingly, we hope that the field can move in a direction of more transparent reflexive engagement with questions and dilemmas regarding ethical practice in both its general orientation and in its encounters with its many and varied research participants.

[Word count 3978] 


\section{References}

BSA [British Sociological Association] (2004) Statement of Ethical Practice for the British Sociological Association. Available at

http://www.britsoc.co.uk/user_doc/Statement\%20of\%20Ethical\%20Practice.doc

[Accessed 14 ${ }^{\text {th }}$ April 2008]

Corden, A. and Sainsbury, R. (2005) Verbatim quotations: whose views count. The

Qualitative Researcher, Issue 1, pp. 4-6, Available at

http://www.cardiff.ac.uk/socsi/qualiti/QualitativeResearcher [Accessed 28th

March.2008]

Cox, P., Niewöhner, J., Pidgeon, N., Gerrard, S., Fischhoff, B. and Riley, D. (2003)

The use of mental models in chemical risk protection: developing a generic workplace methodology. Risk Analysis, 23, 311-324.

Economic and Social Research Council (2005) Research Ethics Framework

(Swindon: Economic and Social Research Council) Available at

http://www.esrcsocietytoday.ac.uk/ESRCInfoCentre/Images/ESRC Re Ethics Frame _tcm6-11291.pdf [Accessed 14th April 2008].

Fischhoff, B. (1990) Psychology and public policy: tool or toolmaker? American Psychologist, 45, pp. 647-653.

Giddens, A. (1991) Modernity and Self-identity: Self and Society in the Late

Modern Age (Cambridge, Polity Press) 
Graham, J., Grewal, I. and Lewis, J. (2007) Ethics in Social Research: the views of research participants (London, Government Research Unit, HM Treasury) Available at

http://www.gsr.gov.uk/downloads/professional_guidance/ethics_in_gsr/ethics_partici pants.pdf [Accessed 11.4.08]

Hallowell, N. (2006) Varieties of suffering: living with the risk of ovarian cancer.

Health, Risk and Society, 8(1):9 - 26.

Henwood, K.L., Pidgeon, N.F, Sarre, S., Simmons, P. and Smith, N. (forthcoming).

Risk, framing and everyday life: epistemological and methodological reflections from three socio-cultural projects. Health, Risk and Society.

Irwin, A., Simmons, P. \& Walker, G., (1999) Faulty environments and risk reasoning: the local understanding of industrial hazards. Environment and Planning A, 31, pp. 1311-26.

Janis, I.L. ands Mann, L. (1977) Decision Making: A Psychological Analysis of Conflict, Choice and Commitment. (New York, Free Press).

Langford, I. H. (2002) An existential approach to risk perception. Risk Analysis, 22, 101-120. 
Lewis, J. with Datta, J. and Sarre, S. (1999) Individualism and Commitment in Marriage and Cohabitation Research Series no.8/99 (London, Lord Chancellor's Department).

Lincoln, Y S. and Guba, E. G. (1985). Naturalistic Inquiry (Newbury Park, Sage).

Murphy, E. and Dingwall, R. (2003) Qualitative Methods in Health Policy

Research London: Sage.

Pidgeon, N.F. and Gregory, R. (2004) Judgment, decision making and public policy, in: D. Koehler and N. Harvey (eds.) Blackwell Handbook of Judgment and Decision Making. pp 604-623 (Oxford, Blackwell).

Poortinga, W. and Pidgeon, N.F. (2003) Exploring the dimensionality of trust in risk regulation. Risk Analysis, 23, 961-972.

Social Research Association (SRA) Ethical Guidelines, Dec. 2003. Available at: www.the-sra.org.uk/documents/pdfs/ethics03 [Accessed 28.03.08].

Rosa, E.A. (2003) The logical structure of the social amplification of risk framework (SARF): Metatheoretical foundations and policy implications, in: Pidgeon, N.F.,

Kasperson, R.K. and Slovic, P. (Eds) (2003) The Social Amplification of Risk (Cambridge, Cambridge University Press) 
Sharf, B. F. (1999) Beyond netiquette: The ethics of doing naturalistic discourse research on the internet, in: S. Jones (Ed.) Doing Internet Research: Critical Issues and Methods for Examining the Net pp. 243-256 (Thousand Oaks, Sage)

Zonabend, F. (1993). The Nuclear Peninsula (Cambridge, Cambridge University Press). 